\title{
Idh2 Deficiency Exacerbates Acrolein-Induced Lung Injury through Mitochondrial Redox Environment Deterioration
}

\author{
Jung Hyun Park, ${ }^{1}$ Hyeong Jun Ku, ${ }^{2}$ Jin Hyup Lee, ${ }^{1}$ and Jeen-Woo Park ${ }^{2}$ \\ ${ }^{1}$ Department of Food and Biotechnology, Korea University, Sejong, Republic of Korea \\ ${ }^{2}$ School of Life Sciences and Biotechnology, BK21 Plus KNU Creative BioResearch Group, College of Natural Sciences, \\ Kyungpook National University, Taegu, Republic of Korea \\ Correspondence should be addressed to Jin Hyup Lee; jinhyuplee@korea.ac.kr and Jeen-Woo Park; parkjw@knu.ac.kr
}

Received 27 July 2017; Revised 18 October 2017; Accepted 1 November 2017; Published 31 December 2017

Academic Editor: Daniela Giustarini

Copyright ( 2017 Jung Hyun Park et al. This is an open access article distributed under the Creative Commons Attribution License, which permits unrestricted use, distribution, and reproduction in any medium, provided the original work is properly cited.

Acrolein is known to be involved in acute lung injury and other pulmonary diseases. A number of studies have suggested that acrolein-induced toxic effects are associated with depletion of antioxidants, such as reduced glutathione and protein thiols, and production of reactive oxygen species. Mitochondrial $\mathrm{NADP}^{+}$-dependent isocitrate dehydrogenase (idh2) regulates mitochondrial redox balance and reduces oxidative stress-induced cell injury via generation of NADPH. Therefore, we evaluated the role of idh2 in acrolein-induced lung injury using idh2 short hairpin RNA- (shRNA-) transfected Lewis lung carcinoma (LLC) cells and idh2-deficient $\left(i d h 2^{-I}\right)$ mice. Downregulation of idh2 expression increased susceptibility to acrolein via induction of apoptotic cell death due to elevated mitochondrial oxidative stress. Idh2 deficiency also promoted acrolein-induced lung injury in $i d h 2$ knockout mice through the disruption of mitochondrial redox status. In addition, acrolein-induced toxicity in idh2 shRNA-transfected LLC cells and in idh2 knockout mice was ameliorated by the antioxidant, $\mathrm{N}$-acetylcysteine, through attenuation of oxidative stress resulting from idh2 deficiency. In conclusion, idh2 deficiency leads to mitochondrial redox environment deterioration, which causes acrolein-mediated apoptosis of LLC cells and acrolein-induced lung injury in idh2 ${ }^{-1-}$ mice. The present study supports the central role of $i d h 2$ deficiency in inducing oxidative stress resulting from acrolein-induced disruption of mitochondrial redox status in the lung.

\section{Introduction}

Acrolein is a ubiquitous environmental pollutant that arises from cigarette smoke, incomplete combustion of plastic materials, and pyrolyzed animal and vegetable; it is also endogenously produced during inflammation or oxidation of unsaturated lipids [1]. Acrolein inhalation results in the induction of gene regulation, inflammation, and lung cell apoptosis and necrosis [1]. It has been reported that exposure to acrolein leads to acute lung injury, disruption of alveolar capillary barrier integrity, pulmonary edema, and chronic obstructive pulmonary disease $[2,3]$.

It has been reported that acrolein causes oxidative stress by inducing, directly or indirectly, the production of excessive reactive oxygen species (ROS) that promote cellular apoptosis $[4,5]$. ROS play a particularly important role in acrolein-induced cellular damage because acrolein is one of the most reactive $\alpha, \beta$-unsaturated aldehyde products of lipid peroxidation [6,7]. As an $\alpha, \beta$-unsaturated aldehyde, acrolein contains a highly reactive carbonyl group and an electrophilic $\alpha$-carbon that is highly reactive to cellular nucleophiles, such as proteins, DNA, and RNA [7]. Acrolein readily targets and reacts with the sulfhydryl group of cysteines to form thioether adducts via a Michael addition mechanism [8]. Depletion of cellular reduced glutathione (GSH) by the formation of GS-acrolein conjugates results in increased oxidative stress [9-11]. Acrolein can also deplete protein thiols, such as thioredoxin and glutaredoxin, which are important antioxidant proteins $[12,13]$.

Acrolein has also been reported as a mitochondrial toxicant, suggesting that it participates in mitochondrial dysfunction [14]. The mitochondria are one of the most important organelles involved in the production of ROS because the respiratory chain in the mitochondria is one of 
major sources of ROS production [15]. Additionally, these are also the main targets of ROS and oxidative stressinduced damage, as observed in various pathological states $[16,17]$. Under normal physiological conditions, cell viability and function are critically dependent on the continued balance between mitochondrial ROS formation and removal [18]. ROS can be eliminated by antioxidant enzymes, such as superoxide dismutases, catalase, glutathione peroxidase, and peroxiredoxins (Prxs) [19]. In this regard, knockdown or inhibition of antioxidant enzymes can disrupt redox balance and exacerbate ROS-induced cell death. To maintain GSHdependent mitochondrial antioxidant defense systems, the availability of the mitochondrial NADPH pool is critical [20]. In addition, the mitochondrial thioredoxin system, which includes thioredoxin 2 (TRX2) and thioredoxin reductase 2 (TRXR2), provides a disulfide reductase activity that is required for maintaining mitochondrial proteins in their reduced state. The mitochondrial thioredoxin system can interact with Prx3, exclusively detected in the mitochondria. Reduced TRX2 is regenerated by TRXR 2 at the expense of NADPH [18]. The major enzyme to generate mitochondrial NADPH is the mitochondrial isoenzyme of $\mathrm{NADP}^{+}$dependent isocitrate dehydrogenase (IDH2) [21, 22]. Thus, suppression of IDH2 activity may induce an imbalance of the mitochondrial redox state that subsequently increases the vulnerability of lung cells and tissues to acrolein-based modulation of the redox status.

The present study demonstrates that acrolein exposure promotes the inhibition of $i d h 2$ expression, lowers the cell reduction potential, and increases ROS levels. Suppression of $i d h 2$ expression led to disruption of mitochondrial redox status, induction of apoptosis, and acute injury in the lung of idh2-deficient $\left(i d h 2^{-/-}\right)$mice and idh2 short hairpin RNA- (shRNA-) transfected cells. These results suggest that attenuation or deficiency of idh2 leads to increased mitochondrial ROS levels that causes acrolein-mediated apoptosis of Lewis lung carcinoma (LLC) cells and acrolein-induced lung injury in $i d h 2^{-1-}$ mice. The findings of the present study support a significant role for increased ROS resulting from disruption of mitochondrial antioxidant defense via suppression of IDH2 expression in acrolein-induced acute lung injury.

\section{Materials and Methods}

2.1. Materials. Propidium iodide (PI), 5,5',-dithio-bis(2nitrobenzoic acid), 3-(4,5-dimethylthiazol-2-yl)-2,5-di-phenyltetrazolium bromide (MTT), anti-rabbit IgG tetramethylrhodamine isothiocyanate- (TRITC-) conjugated secondary antibody, xylenol orange, N-acetyl-L-cysteine (NAC), and rhodamine 123 (Rh-123) were purchased from SigmaAldrich (St. Louis, MO), while $2^{\prime}, 7^{\prime}$-dichloro-fluorescin diacetate (DCFH-DA), diphenyl-1-pyrenylphosphine (DPPP), $3^{\prime}$-tetraethylbenzimidazolocarbocyanine iodide (JC-1), 5chloromethylfluorescein diacetate (CMFDA), and MitoSox were purchased from Invitrogen (Eugene, OR). The antibodies used in this study were as follows: $\beta$-actin and cellular tumor antigen p53 (Santa Cruz Biotechnology, Santa Cruz, CA); p-JNK, cleaved-PARP, cleaved caspase-3, cleaved caspase-9, and horseradish peroxidase- (HRP-) conjugated secondary antibodies (Cell Signaling Technology, Beverly, MA); apoptosis regulator BAX (Calbiochem, San Diego, CA); acrolein adducts (Abcam, Cambridge, $\mathrm{MA}$ ); and oxidized $\operatorname{Prx}\left(\operatorname{Prx}-\mathrm{SO}_{3}\right)$ (Abfrontier, Seoul, Korea). A peptide containing the $16 \mathrm{~N}$-terminal amino acids of mouse IDH2 (ADKRIKVAKPVVEMPG) was used to prepare polyclonal anti-IDH2 antibodies.

2.2. Cell Culture. The LLC cell line was purchased from the Japanese Collection of Research Bioresources Cell Bank (JCRB Cell Bank, Osaka, Japan). Cells were cultured using Dulbecco's modified Eagle's medium supplemented with $10 \%$ fetal calf serum and $1 \%$ penicillin/streptomycin in a humidified atmosphere at $37^{\circ} \mathrm{C}$ and $5 \% \mathrm{CO}_{2}$. After $48 \mathrm{~h}$, the plates were washed with phosphate-buffered saline (PBS) and incubated with new medium containing acrolein, while the same quantity of PBS was used as the control. Cells were cultivated in a humidified atmosphere at $37^{\circ} \mathrm{C}$ and $5 \% \mathrm{CO}_{2}$ and harvested after acrolein exposure. The MTT assay was used to determine cell cytotoxicity as previously described [23].

2.3. Idh2 shRNA Knockdown. Idh2 shRNA and nontarget shRNA MISSION ${ }^{\circledR}$ lentiviral transduction particles were purchased from Sigma-Aldrich. LLC cells were transduced with a final concentration of $8 \mu \mathrm{g} / \mathrm{mL}$ hexadimethrine bromide, according to the manufacturer's protocol. Transduced cells were selected as single colonies in a medium containing $5 \mu \mathrm{g} / \mathrm{mL}$ puromycin (Clontech, Mountain View, CA) and maintained in a medium containing $1 \mu \mathrm{g} / \mathrm{mL}$ puromycin.

2.4. RNA Isolation and Reverse Transcription Polymerase Chain Reaction (RT-PCR). The RNA was extracted from LLC cells using an RNeasy kit (Qiagen, Hilden, Germany) in accordance with the manufacturer's instructions. RNA was reverse transcribed to cDNA using a first-strand cDNA synthesis kit (Invitrogen), according to the manufacturer's protocol. cDNAs were PCR-amplified. Sequences of the primers used were as follows: $\beta$-actin, forward: $5^{\prime}$-TCTACA ATGAGCTGCGTGTG- ${ }^{\prime}$, reverse: $5^{\prime}$-ATCTCCTTCTG CATCCT-GTC- $3^{\prime}$ and $i d h 2$, forward: $5^{\prime}$-ATCAAGGAGAA GC-TCATCCTGC-3', reverse: $5^{\prime}$-TCTGTGGCCTTGTACT GGTCG- ${ }^{\prime}$. $\beta$-Actin was used as an internal control. The amplified DNA products were resolved on a $1 \%$ agarose gel and stained with ethidium bromide.

2.5. Flow Cytometric Analysis. Cells were collected at $2000 \mathrm{~g}$ for $5 \mathrm{~min}$ and washed twice with cold PBS. Annexin V and PI staining were performed with the Alexa Fluor 488 Annexin V/Dead Cell Apoptosis Kit, according to the manufacturer's protocol. The stained cells were analyzed by flow cytometry (BD Biosciences, Franklin Lakes, NJ).

2.6. Assessment of Cellular Redox Status. Intracellular peroxide levels were measured using the ferric-sensitive dye xylenol orange and DCFH-DA as previously described [21]. Protein oxidation was assessed by immunoblot analysis using anti-Prx- $\mathrm{SO}_{3}$ antibody. Intracellular GSH levels were 
measured using a GSH-sensitive fluorescent dye, CMFDA. Cells were stained with $5 \mu \mathrm{M}$ CMFDA for $30 \mathrm{~min}$ at $37^{\circ} \mathrm{C}$.

2.7. Cellular Oxidative Damage. Thiobarbituric acid-reactive substances (TBARS) were used for measurement of lipid peroxidation. Cell extracts were mixed with $1 \mathrm{~mL}$ TBA solution [0.375\% thiobarbituric acid in $0.25 \mathrm{~N} \mathrm{HCl}$ containing $15 \%$ $(w / w)$ trichloroacetic acid] [21]. Lipid peroxidation was also detected by using a fluorescent DPPP probe [24]. The levels of 8-hydroxy-2' -deoxyguanosine (8-OH-dG) in LLC cells were measured with a fluorescent binding assay as described previously [25]. Cells were fixed and permeabilized with icecold methanol for $15 \mathrm{~min}$. DNA damage was visualized with avidin-conjugated TRITC ( $1: 200$ dilution) using a fluorescence microscope. The comet assay was also performed using the Comet Assay Kit (Cell Biolabs Inc., San Diego, CA). Cell extracts were washed with cold PBS and centrifuged. The cell pellet was mixed with Comet Agarose at 1:10 ratio $(v / v)$ and pipetted onto the Comet assay slide. Slides were dried at $4^{\circ} \mathrm{C}$ in the dark for $15 \mathrm{~min}$ and incubated in chilled lysis solution at $4^{\circ} \mathrm{C}$ in the dark for another $15 \mathrm{~min}$. After washing with TBE buffer ( $50 \mathrm{mM}$ Tris, $50 \mathrm{mM}$ boric acid, and $0.2 \mathrm{mM}$ EDTA), the samples were subjected to electrophoresis and stained with Vista Green DNA Dye. Images were obtained with a microscope. The percentage of tail DNA of the cells in each slide was measured and quantified.

2.8. Measurement of Mitochondrial Redox Status and Damage. Healthy mitochondrial membrane potentials were detected using the fluorescent probe JC-1 (Invitrogen). Cells were incubated at $37^{\circ} \mathrm{C}$ with $5 \mu \mathrm{M} \mathrm{JC}-1$ for $30 \mathrm{~min}$. The ratio of the intensity of green/red fluorescence is directly proportional to the mitochondrial membrane potential [26]. The mitochondrial membrane permeability transition (MPT) was visualized using the fluorescent probe Rh-123, and mitochondrial ROS level was measured using MitoSox. Cells were grown in $100 \mathrm{~mm}$ plates containing a slide glass coated with poly-L-lysine and treated with acrolein or PBS and were treated for $30 \mathrm{~min}$ with $5 \mu \mathrm{M}$ each of Rh-123 and MitoSox. Slides with cells on top were washed in warm PBS and covered with a glass cover slip. Rh-123 fluorescence (excitation/emission: 500/536 nm) and oxidized MitoSox red fluorescence (excitation/emission: $510 / 580 \mathrm{~nm}$ ) were imaged on a Zeiss Axiovert 200 inverted microscope and a Zeiss LSM700 confocal laser scanning microscope, respectively.

2.9. Immunoblot Analysis. Total protein extracts were separated on $10-15 \%$ sodium dodecyl sulfate (SDS)-polyacrylamide gels and transferred to nitrocellulose membranes. The membranes were incubated with specific primary antibodies overnight at $4^{\circ} \mathrm{C}$, and the immunoreactive antigen was recognized using HRP-conjugated secondary antibodies and an enhanced chemiluminescence detection kit (GE Healthcare, Buckinghamshire, UK).

2.10. Animals. All animal experiments were reviewed and approved by the Kyungpook National University Institutional Animal Care and Use Committee. Experiments were performed using 8-week-old male C57BL/6 mice with different genotypes, including wild-type (WT) $i d h 2^{+/+}$and knockout $i d h 2^{-l-}$ mice generated by breeding and identified by PCR genotyping, as previously described [27]. The mice were housed in microisolator rodent cages at $22^{\circ} \mathrm{C}$ with a $12 \mathrm{~h}$ light/dark cycle and allowed free access to water and standard mouse chow. Mice were divided into five groups, with 6-10 mice per group (WT, WT + acrolein, KO, $\mathrm{KO}+$ acrolein, and $\mathrm{KO}+$ acrolein $+\mathrm{NAC})$. Mice were subjected to acute acrolein inhalation ( $10 \mathrm{ppm}$ for $12 \mathrm{~h}$ ), where NAC was intraperitoneally administered $(500 \mathrm{mg} / \mathrm{kg}) 2 \mathrm{~h}$ before acrolein exposure.

2.11. Histological Analysis. For histological analysis, the lung tissues were isolated from mice after acrolein treatment and fixed in $4 \%$ formalin. Paraffin lung sections $(5 \mu \mathrm{m})$ were stained with hematoxylin and eosin (H\&E) stain. Slides containing the lung sections were stained sequentially with hematoxylin gill number 3 , bluing solution, and eosin $\mathrm{Y}$ by gently shaking at room temperature. To determine the airspace enlargement in the lungs [28], airspace areas were measured using ImageJ software. Lung injury was graded from 0 (normal) to 4 (severe) in four categories: interstitial inflammation, neutrophil infiltration, congestion, and edema [29]. Lung-injury score was calculated by adding the individual scores for each category. Grading was performed by an observer unaware of the treatment groups.

2.12. Terminal Deoxynucleotidyl Transferase-Mediated dUTP Nick-End Labeling (TUNEL) Staining. To evaluate apoptosis, the lung tissue sections were used for TUNEL staining using the In Situ Cell Death Detection Kit (Roche, Basel, Switzerland), according to the manufacturer's recommended protocol. TUNEL-stained slides were lightly counterstained with $4^{\prime}, 6$-diamidino-2-phenylindole (DAPI) before final mounting. The stained slides were analyzed under an Axiovert 40 CFL microscope (Carl Zeiss AG; Oberkochen, Germany).

2.13. Statistical Analysis. Results are shown as the mean \pm SD. Analyses were performed using a two-tailed $t$-test. $p$ values $<0.05$ were considered statistically significant.

\section{Results and Discussion}

3.1. Knockdown of idh2 Exacerbates Cellular Apoptosis in Acrolein Insult. To investigate the role of IDH2 in acroleininduced toxicity, we silenced the expression of idh2 with shRNA. LLC cells were transfected with shRNA-encoding LVs targeting the transcript of murine idh 2 and were assayed to endogenously generate small RNA that mediates silencing of idh2. RT-PCR analysis revealed a significant decrease in idh2 mRNA levels in idh2 shRNA-transfected cells compared with nontarget shRNA-transfected cells, and immunoblot analysis revealed reduction in IDH2 protein expression levels in vector-infected cells (Figure 1(a)). To examine the effect of idh2 knockdown on cell survival following acrolein treatment, LLC cells were treated with $25 \mu \mathrm{M}$ acrolein for $1 \mathrm{~h}$. Acrolein treatment led to a significant decline in the viability of nontarget shRNA-transfected cells (Figure 1(b)). The effects of idh2 knockdown on the cellular features of apoptosis were also examined. Figure 1(c) shows a typical cell cycle 


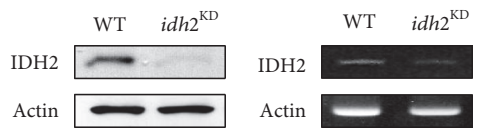

(a)
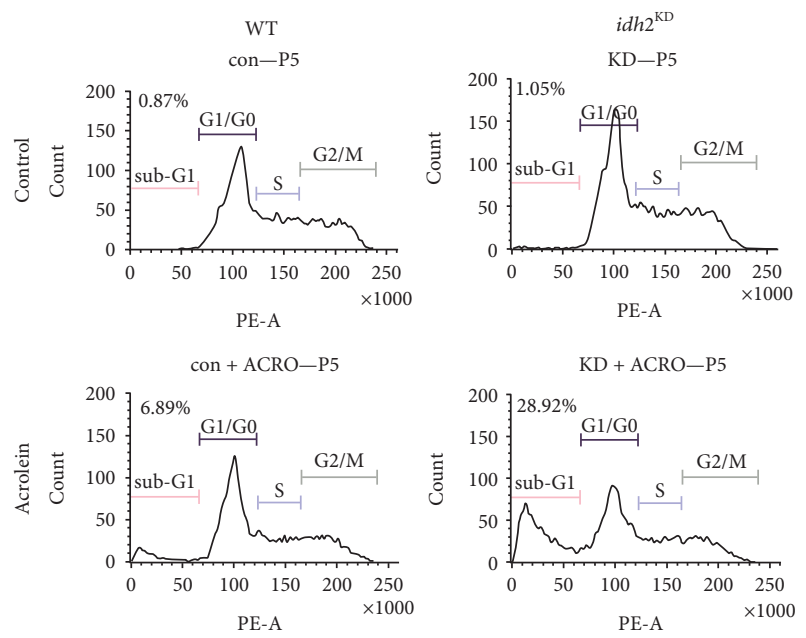

(c)
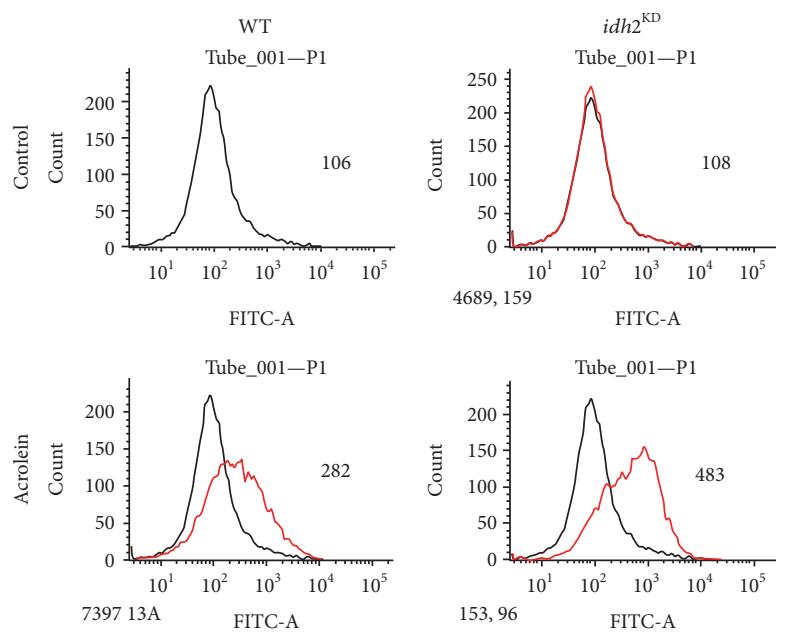

(e)



(b)
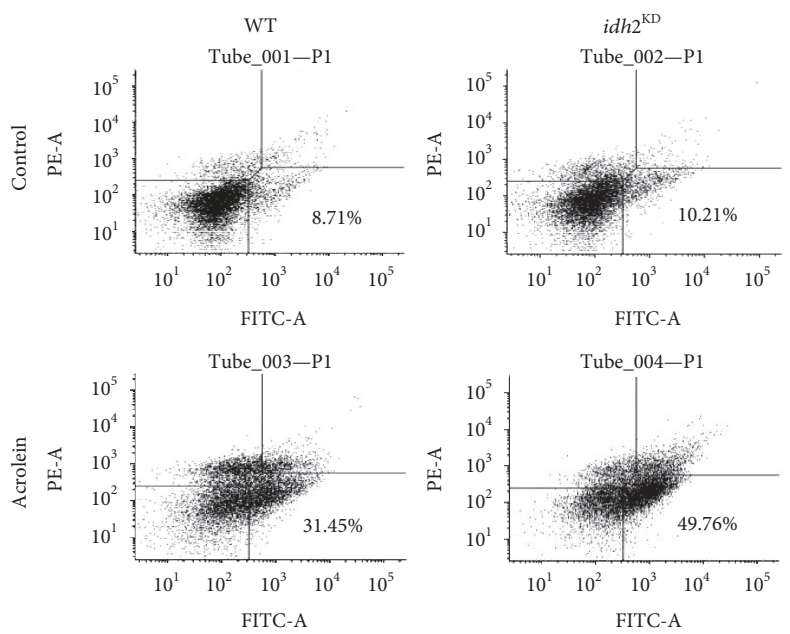

(d)

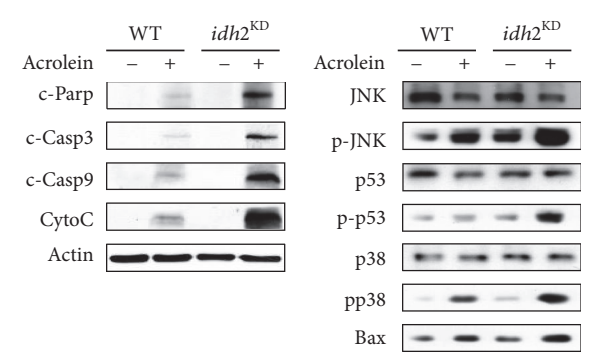

(f)

FIGURE 1: Idh2 knockdown in LLC cells and their vulnerability to acrolein. (a) idh2 protein expression levels were measured by immunoblotting using anti-idh2 antibody. RT-PCR analysis of gene expression in WT and idh2 knockdown (idh $2^{\mathrm{KD}}$ ) LLC cells. $\beta$-Actin was used as an internal control for the experiment. (b) Viability of control and $i d h 2^{\mathrm{KD}}$ LLC cells. Cells were cultured for 2 days at $37^{\circ} \mathrm{C}$, exposed to $25 \mu \mathrm{M}$ acrolein for $1 \mathrm{~h}$, and cell viability was then evaluated using MTT assay. Data are presented as the mean \pm SD of four independent experiments. ${ }^{*} p<0.05$ versus WT cells exposed to acrolein. (c) The ratio of cells undergoing apoptosis was measured by FACS. (d) Apoptosis was measured with FITC-labeled annexin in conjunction with PI. Cells were analyzed by flow cytometry. The lower right quadrants represent apoptotic cells. (e) Evaluation of apoptosis with annexin V by FACS. (f) Immunoblot analysis of apoptosis-related proteins. Control and $i d h 2^{\mathrm{KD}}$ cells were exposed to $25 \mu \mathrm{M}$ acrolein for $1 \mathrm{~h}$. Cell extracts were electrophoresed on 10-15\% SDS-polyacrylamide gels, transferred to nitrocellulose membranes, and immunoblotted with antibodies against cleaved caspase-3 (c-Casp3), cleaved caspase-9 (c-Casp9), cleaved PARP (c-PARP1), cytochrome c, p53, p-p53, p38, p-p38, JNK, p-JNK, and BAX. $\beta$-Actin was used as an internal control. 

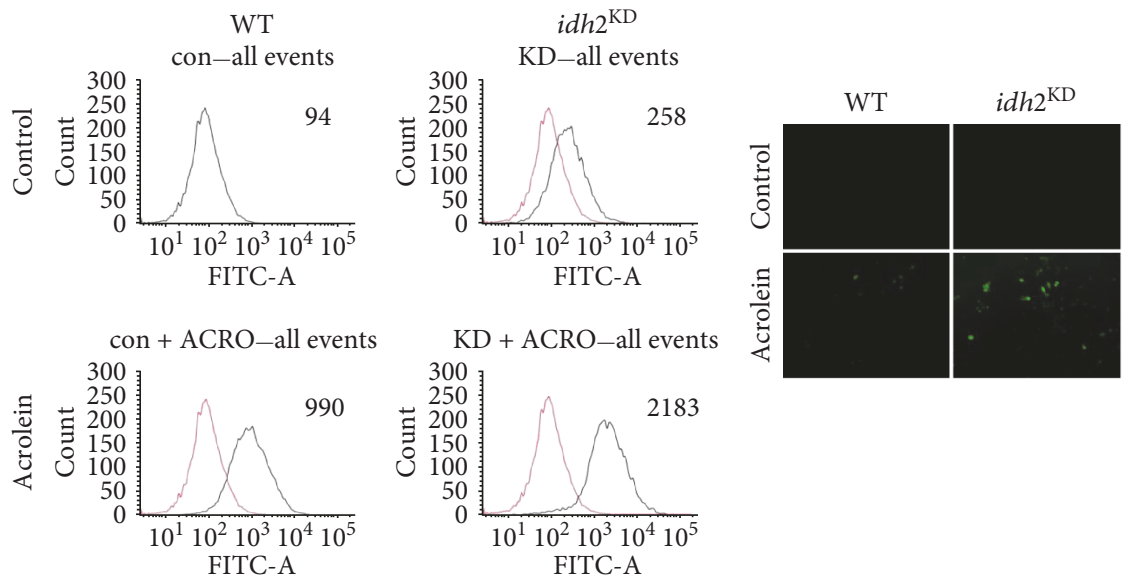

(a)

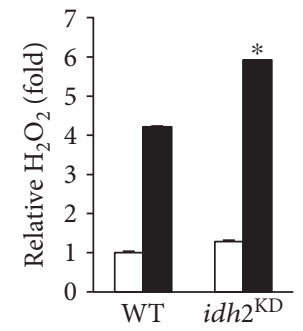

$\square$ Control

Acrolein

(b)
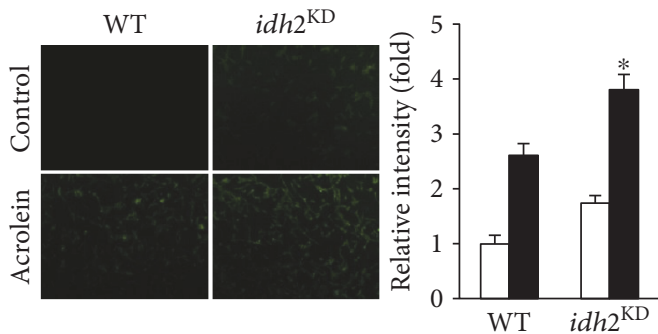

$\square$ Control

口 Acrolein

(e)



$\square$ Control

- Acrolein

(d)

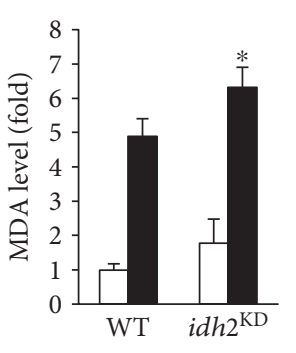

$\square$ Control

- Acrolein

(f)

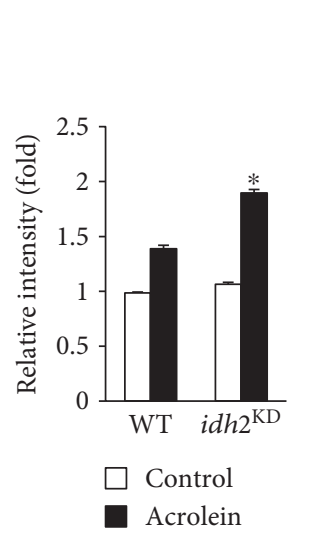

(g)

$$
\text { Acrolein } \frac{\mathrm{WT}}{-+} \frac{i d h 2^{\mathrm{KD}}}{-+}
$$
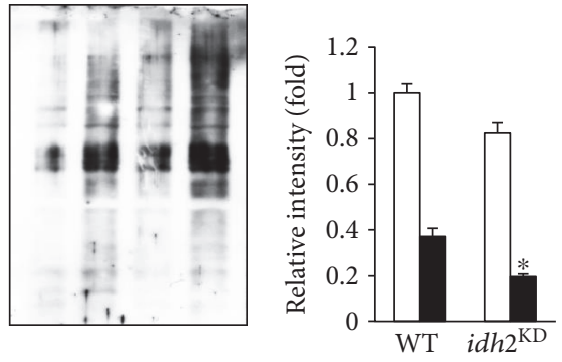

$$
\square \text { Control }
$$$$
\text { - Acrolein }
$$

(h)

(i)

Figure 2: Continued. 


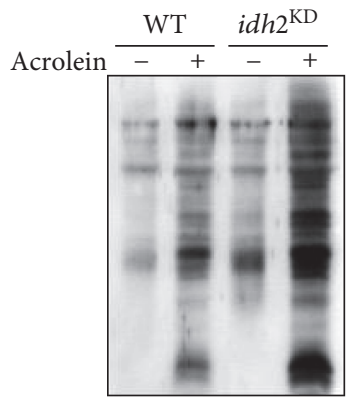

(j)

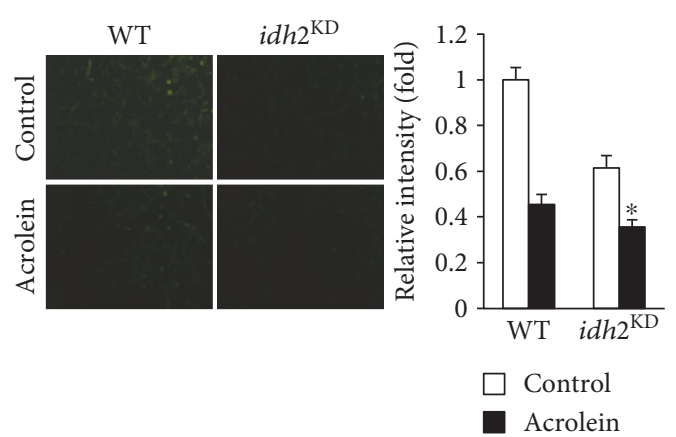

(k)

FIGURE 2: Effect of $i d h 2$ knockdown on cellular redox status and oxidative damage in LLC cells exposed to acrolein. (a) LLC cells were stained with DCFH-DA for $30 \mathrm{~min}$ and DCF fluorescence was measured by flow cytometry and fluorescence microscopy. (b) Hydrogen peroxide production in LLC cells was measured by xylenol orange. (c) Immunoblot analysis of Prx-SO levels in LLC cell lysates. (d) Comet assay analysis of LLC cells and the tail/core width ratio obtained from captured images. (e) The levels of 8-OH-dG were measured by fluorescence microscopy. The average fluorescence intensity was calculated as previously described [44]. (f) The level of MDA accumulated in LLC cell extracts was determined using TBARS assay. (g) Cellular lipid peroxidation was measured with DPPP. The average fluorescence intensity was calculated as previously described [44]. (h) The level of oxidized protein adducts in the lung tissue extracts was measured with an anti-DNP antibody. (i) Fluorescence images of CMFDA-loaded cells were obtained under a microscope to evaluate cellular GSH levels. The average fluorescence intensity was calculated as previously described [44]. (j) The level of glutathionylated protein adducts in the lung tissue extracts was measured with an anti-GSH antibody. (k) Cellular NADPH level was determined by immunofluorescence using an anti-NADPH antibody. The average fluorescence intensity was calculated as previously described [44]. In (b), (d-g), (i), and (k), data are presented as the mean \pm SD of four independent experiments. ${ }^{*} p<0.05$ versus WT cells exposed to acrolein.

plot of LLC cells that were transfected with control or idh2 shRNA. The number of apoptotic cells was estimated by calculating the number of subdiploid cells in the cell cycle histogram. The number of apoptotic cells was markedly increased among the idh2 shRNA-transfected cells compared to the control cells upon exposure to acrolein. To determine whether apoptosis is responsible for the vulnerability of $i d h 2-$ silenced LLC cells to acrolein-induced cell damage, apoptotic cells were quantified using flow cytometry and PI/annexin V dual staining. The quantitative results in Figure 1(d) show that most of the acrolein-treated cells were in the early stage of apoptosis (depicted in the lower right quadrants). Similar results were also observed using the Annexin-V-FLUOS staining kit (Roche) with fluorescence-activated cell sorting (FACS) (Figure 1(e)). Idh2-silenced LLC cells were more vulnerable to acrolein-induced apoptotic cell death than their WT counterparts. The effect of idh 2 knockdown on the modulation of apoptotic marker proteins was also examined in LLC cells. As shown in Figure 1(f), caspase- 3 and caspase- 9 cleavages were more pronounced in the idh2 shRNAtransfected cells. The formation of fragments indicative of proteolytic PARP cleavage, a proapoptotic marker, was significantly increased in idh2 shRNA-transfected cells compared to control cells. In order to determine the role of IDH2 in acrolein-induced toxicity in the mitochondrial apoptotic pathway, the expression level of cytochrome $c$ was evaluated. Upon exposure to acrolein, the level of cytochrome $c$ was markedly increased in cells that were transfected with idh2 shRNA (Figure 1(f)). The levels of proapoptotic proteins such as BAX were also significantly increased in idh2
shRNA-transfected cells compared to control cells. To further evaluate the effect of idh2 downregulation on the proapoptotic signaling pathway, the activation of p53 and JNK was examined by immunoblot analysis. The levels of phospho-p53 and phospho-JNK increased in cells that were transfected with idh2 shRNA and treated with acrolein (Figure 1(f)). Activation of p38 has been implicated in the induction of apoptosis [30]. As shown in Figure 1(f), the level of phospho-p38 increased in LLC cells transfected with idh2 shRNA upon exposure to acrolein. These findings reveal for the first time that IDH2 plays a vital role in LLC cell function and survival against acrolein toxicity.

3.2. Modulation of Redox Status by idh2 Knockdown in Acrolein Toxicity. Excessive ROS are detrimental because they cause nonspecific oxidative damage to cellular components, DNA, proteins, lipids, and other macromolecules $[31,32]$. In addition, ROS modulate redox homeostasis and redox-regulated signaling cascades, thereby causing further damage to tissues and cellular compartments [33]. To determine whether differences in susceptibility to acrolein toxicity between control and idh2 shRNA-transfected cells were associated with ROS formation, the levels of intracellular peroxides in the cells were measured by FACS using the oxidantsensitive probe, DCFH-DA. As shown in Figure 2(a), markedly increased ROS levels were observed in idh2 shRNA-transfected cells exposed to acrolein. Furthermore, idh 2 knockdown was accompanied by a substantial elevation in intracellular $\mathrm{H}_{2} \mathrm{O}_{2}$ level, as measured by xylenol orange when cells were exposed to acrolein (Figure 2(b)). Increased 

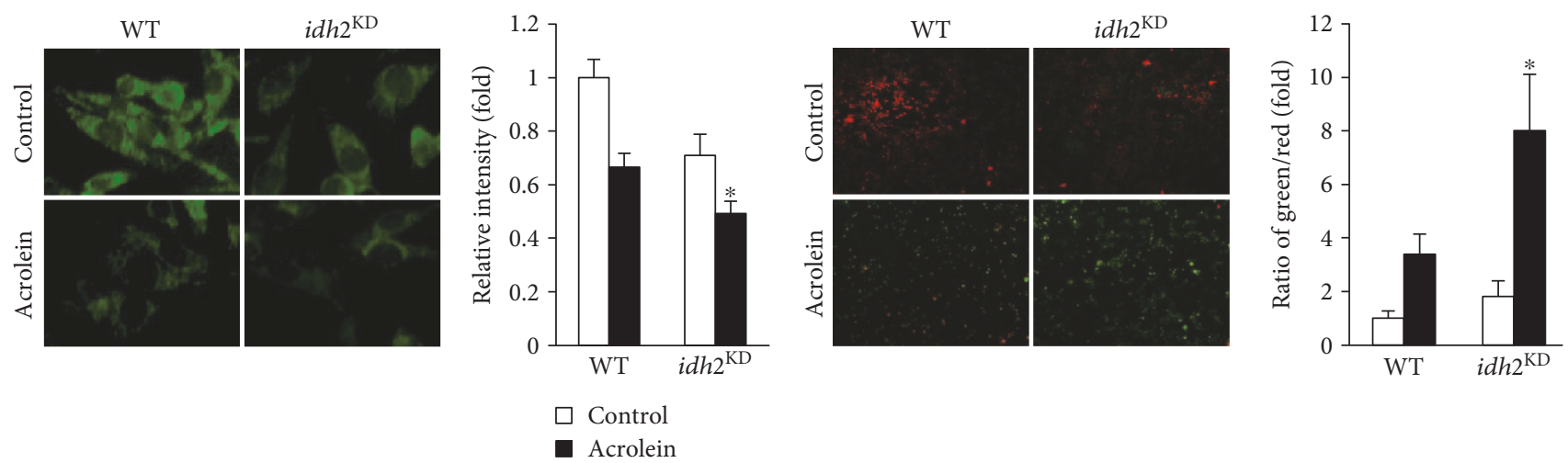

(a)
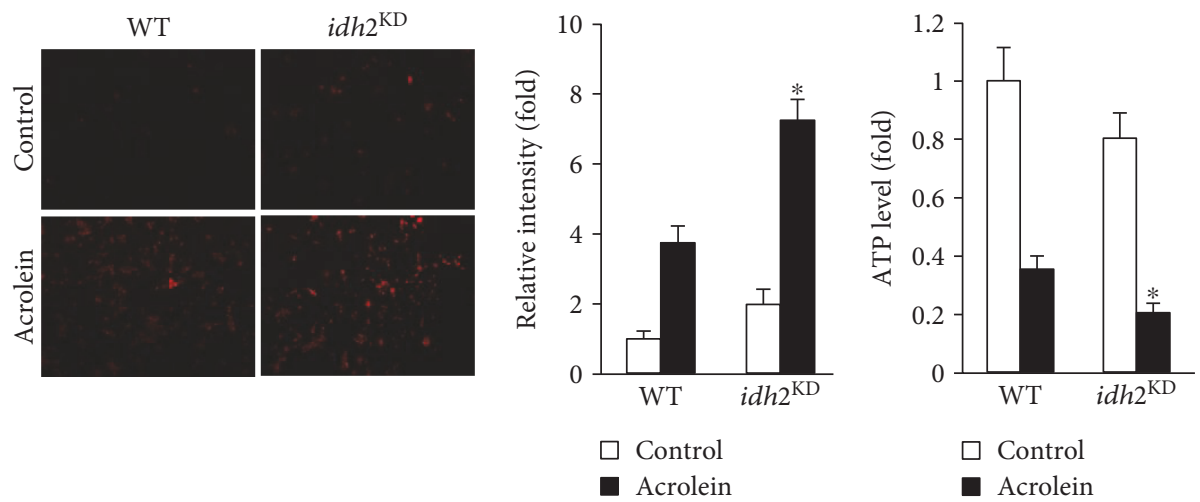

(b)

(c)

(d)

FIgURE 3: Downregulation of idh2 aggravates mitochondrial dysfunction in LLC cells exposed to acrolein. (a) Mitochondrial membrane potential of LLC cells was measured by incorporation of Rh-123 dye into the mitochondria. (b) Membrane potential was analyzed with JC-1 probe. The mean (green/red) fluorescence intensity was expressed as a percentage compared with control. (c) MitoSox was used to detect mitochondrial ROS generation. MitoSox fluorescence was visualized by a fluorescence microscope. In (a-c), the average fluorescence intensity was calculated as previously described [44]. Data are presented as the mean \pm SD of four independent experiments. ${ }^{*} p<0.05$ versus WT cells exposed to acrolein. (d) ATP levels were measured in LLC cells following acrolein treatment. Data are presented as the mean $\pm \mathrm{SD}$ of four independent experiments. ${ }^{*} p<0.05$ versus WT cells exposed to acrolein.

levels of Prx- $\mathrm{SO}_{3}$, a marker for oxidative damage of the antioxidant enzyme Prx [34], were also found in idh2 shRNA-transfected cells exposed to acrolein in comparison with control cells (Figure 2(c)). The occurrence of oxidative DNA damage, lipid peroxidation, and protein oxidation was evaluated as markers indicative of cellular oxidative damage. Next, the overall DNA fragmentation was measured using the Comet assay to evaluate DNA strand breaks induced by oxidative stress. As shown in Figure 2(d), the induction of DNA damage following acrolein treatment was augmented by knockdown of idh2. In this assay, damaged DNA exhibits the shape of a comet in which the tail length relates to the number of DNA strand breaks. To further confirm DNA damage, the level of 8-OH-dG, an indicator of oxidative DNA damage both in vivo and in vitro [25], was determined. After acrolein treatment, the endogenous DNA levels of 8-OH-dG were significantly increased in idh2 shRNA-transfected cells as compared to control cells (Figure 2(e)). Consistent with the elevation of ROS, there was a considerable increase in the level of malondialdehyde (MDA), a lipid peroxidation marker, in idh2 knockdown cells exposed to acrolein (Figure 2(f)). It has been shown that
DPPP is a suitable probe for monitoring lipid peroxidation, specifically within the cell membrane [24]. Upon exposure to acrolein, DPPP fluorescence intensity was markedly increased in idh2 shRNA-transfected cells in comparison with control cells (Figure 2(g)). To determine whether idh2 knockdown increased sensitivity to protein damage, carbonyl contents were measured to evaluate protein oxidation. The carbonyl content of $i d h 2$ shRNA-transfected cells was significantly higher than that of control cells (Figure 2(h)). An alternative method for monitoring oxidative stress within cells involves measuring the cellular levels of GSH, which is closely associated with many effects of acrolein on cell death $[35,36]$, using the GSH-sensitive fluorescent dye CFMDA [37]. Using this technique, GSH levels in idh2 shRNA-transfected cells exposed to acrolein were found to be significantly decreased compared to that in control cells (Figure 2(i)). There are numerous oxidative stress-induced conditions during which the redox status and GSH/GSSG ratio are perturbed [38]. Protein S-glutathionylation is a posttranslational modification of protein sulfhydryl groups that occurs under oxidative stress [39]. The redox status of idh2 shRNA-transfected cells was impaired more than 


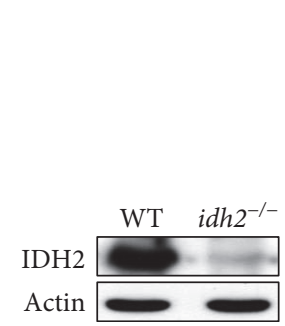

(a)

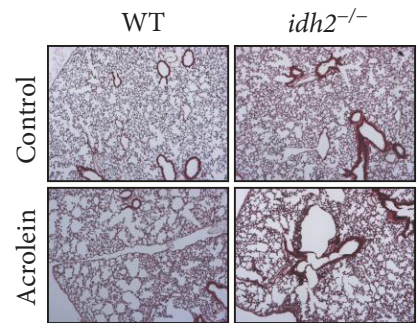

(b)

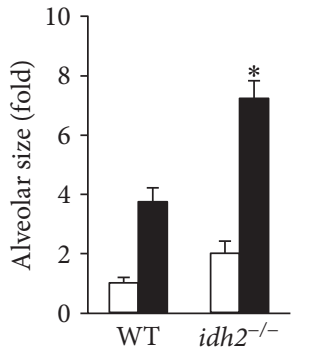

$\square$ Control

- Acrolein

(c)

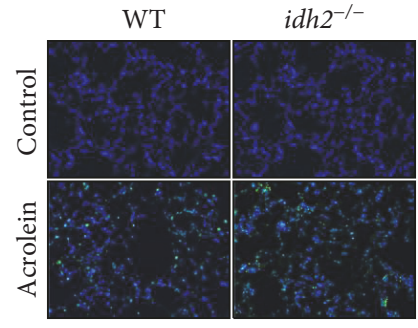

(e)

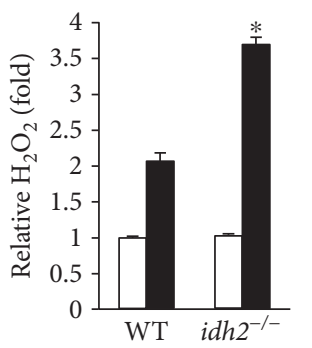

$\square$ Control

- Acrolein

(g)

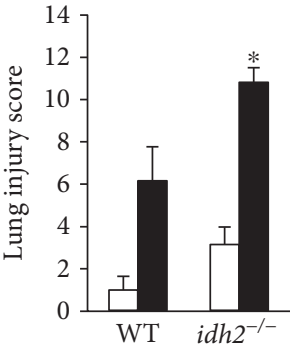

$\square$ Control

- Acrolein

(d) (f)

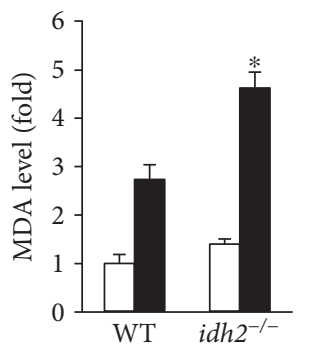

$\square$ Control

- Acrolein

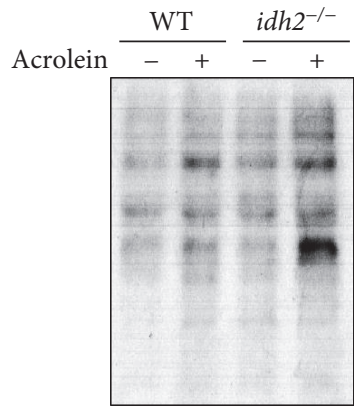

(j) (i)

(h)

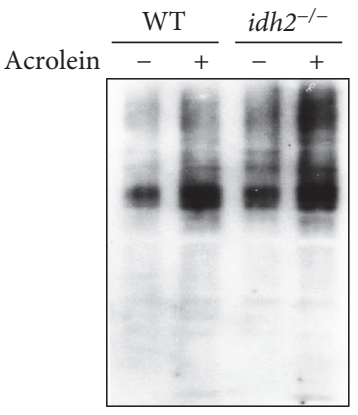

(k)

Figure 4: Continued. 


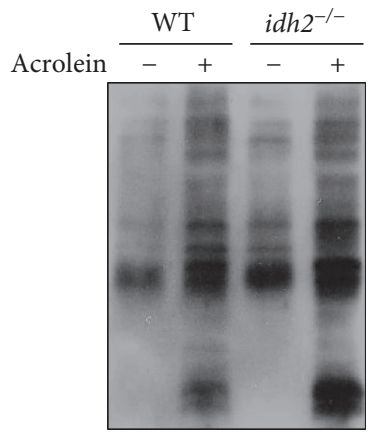

(1)

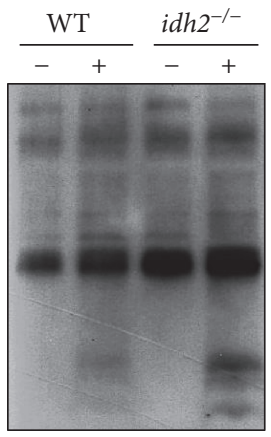

$(\mathrm{m})$

Figure 4: Acrolein-induced lung damage in $i d h 2^{-/-}$mice. Mice were exposed to filtered air (control) or acrolein (10 ppm, $12 \mathrm{~h}$ ). (a) Immunoblot analysis of IDH2 protein expression using an anti-IDH2 antibody. $\beta$-Actin was used as an internal control. (b) H\&E-stained sections of the lung tissues after acrolein exposure. (c) Emphysema in acrolein-treated lung tissues assessed by mean alveolar airspace area $\left(\mu \mathrm{m}^{2}\right)$. (d) Lung injury scores were evaluated after acrolein exposure. (e) TUNEL staining of the lung tissues from acrolein-treated idh2 $2^{-/-}$ and WT $\left(i d h 2^{+/+}\right.$) mice. (f) Immunoblots comparing the levels of apoptotic marker proteins in the lung tissue extracts from acroleintreated $i d h 2^{-1-}$ and WT mice. $\beta$-Actin was used as an internal control. (g) Intracellular $\mathrm{H}_{2} \mathrm{O}_{2}$ was measured using xylenol orange. (h) Immunoblot analysis of Prx- $\mathrm{SO}_{3}$ levels in the lung tissue extracts from WT and idh2 ${ }^{-l-}$ mice. (i) The levels of MDA accumulated in the lung tissue extracts were determined using TBARS assay. (j) The levels of acrolein-adducted proteins in the lung tissue extracts were measured with anti-acrolein antibody. (k) The levels of oxidized protein adducts, (l) glutathionylated protein adducts, and (m) nitrosylated protein adducts in the lung tissue extracts were measured with anti-DNP, anti-GSH, and anti-nitrotyrosine antibodies, respectively. In (c), (d), (g), and (i), data are shown as the mean $\pm \mathrm{SD}\left(n=3-6\right.$ mice in each group). ${ }^{*} p<0.05$ versus acrolein-treated WT mice.

that of control cells, as reflected by an increase in glutathionylated proteins (Figure 2(j)). NADPH, required for GSH generation by glutathione reductase, is an essential factor for cellular defense against oxidative damage. As expected, knockdown of idh2 in LLC cells significantly decreased NADPH levels, which were further decreased upon exposure to acrolein (Figure $2(\mathrm{k})$ ). Taken together, these results indicate that combination of $i d h 2$ knockdown and acrolein exposure markedly elevated ROS generation and subsequently induced oxidative damage in LLC cells.

3.3. Role of idh2 in the Mitochondrial Status Induced by Acrolein. In addition to the essential role of the mitochondria in energy metabolism, regulation of cell death, which presumably is associated with mitochondrial ROS production, has emerged as another major function of these organelles [40]. ROS play a major role in modulation of MPT, an important event in apoptosis [41]. The lipophilic cationic dye Rh-123 was used to determine changes in MPT in LLC cells exposed to acrolein. Acrolein-induced alteration of MPT, which was reflected by a decrease in Rh-123 fluorescence, was greater in idh2 knockdown cells compared with control cells (Figure 3(a)). JC-1 is a fluorescent dye exhibiting potential-dependent accumulation in the mitochondria, which is commonly employed to detect MPT changes [26]. The ratio of green/red fluorescence also demonstrated that treatment of LLC cells with acrolein resulted in decreased MPT, and this effect was exacerbated by knockdown of idh2 expression (Figure 3(b)). To assess whether changes in MPT were accompanied by alterations in intracellular ROS concentrations, the levels of intracellular peroxides in the mitochondria were evaluated using confocal microscopy and the mitochondrial oxidant-sensitive probe MitoSox. As shown in Figure 3(c), following idh2 silencing, there was a marked increase in MitoSox fluorescence intensity after treatment of $i d h 2$ knockdown cells with acrolein. In control cells, this increase in fluorescence intensity was less pronounced, indicating that $i d h 2$ deficiency promotes production of mitochondrial ROS in acrolein-treated cells. The mitochondrial dysfunction in energy metabolism was determined by measuring ATP synthesis [42]. After exposure to acrolein, a significant decrease in ATP production was observed in idh2 shRNA-transfected cells compared with control cells (Figure 3(d)). Taken together, these results indicate that idh2 knockdown is associated with disruption of the mitochondrial redox environment and induction of mitochondrial dysfunction when cells are exposed to acrolein.

3.4. Idh2 Deficiency Promotes Acrolein Toxicity In Vivo. To test the physiological relevance of $i d h 2$ deficiency in acrolein toxicity, WT $\left(i d h 2^{+/+}\right)$mice and mice lacking $i d h 2\left(i d h 2^{-/-}\right)$ were exposed to $10 \mathrm{ppm}$ acrolein for $2 \mathrm{~h}$ or filtered air (control). As expected, protein expression of IDH2 was not detected in the lung tissues harvested from $i d h 2^{-1-}$ mice (Figure 4(a)). Histological analysis of the lung tissue showed that acrolein caused enlargement of alveolar and immune cell infiltration, and these histological characteristics were dramatically enhanced in $i d h 2^{-/}$mice compared with $i d h 2^{+/+}$ mice (Figure 4(b)). The significant increase in susceptibility of $i d h 2^{-l-}$ mice to acrolein-induced lung injury was also reflected by a significant increase in alveolar airspace area (Figure 4(c)) and lung injury score (Figure 4(d)). To gain further insights into the effect of IDH2 on lung damage in acrolein-treated mice, the effect of idh2 deficiency on the process of apoptosis was studied. As shown in Figure 4(e), more TUNEL-stained spots were observed in the lung tissues of $i d h 2^{-1-}$ mice compared with WT mice. Western blot 


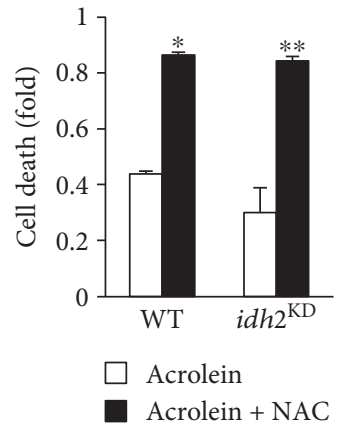

(a)

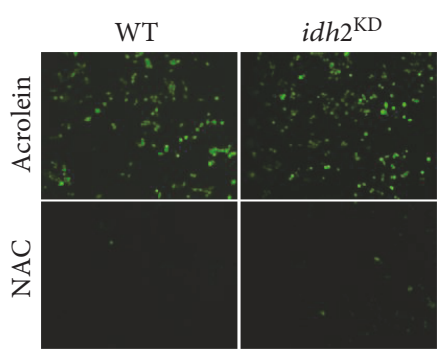

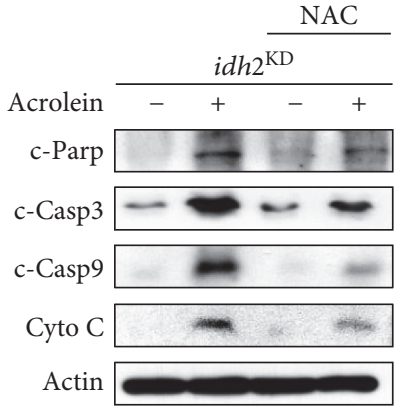

(b)
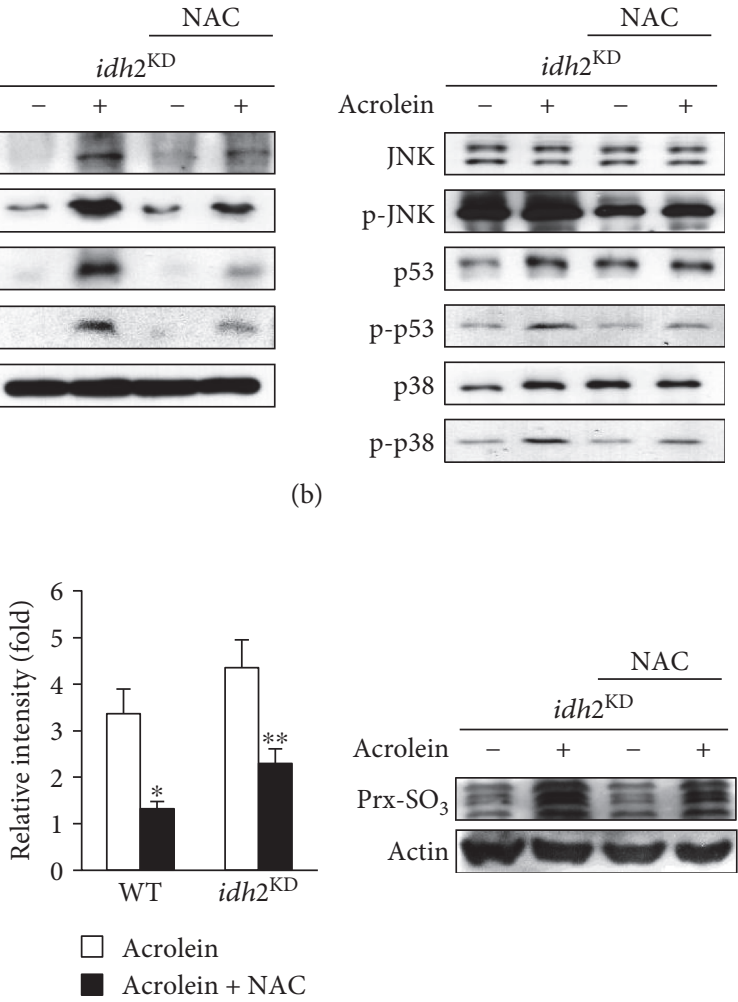

(d)

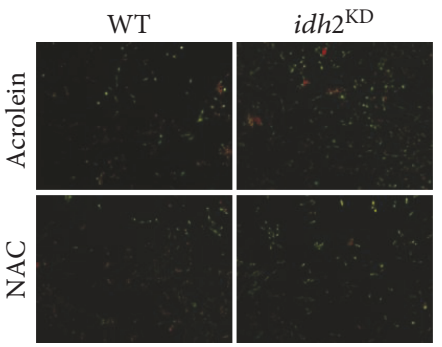

(c)
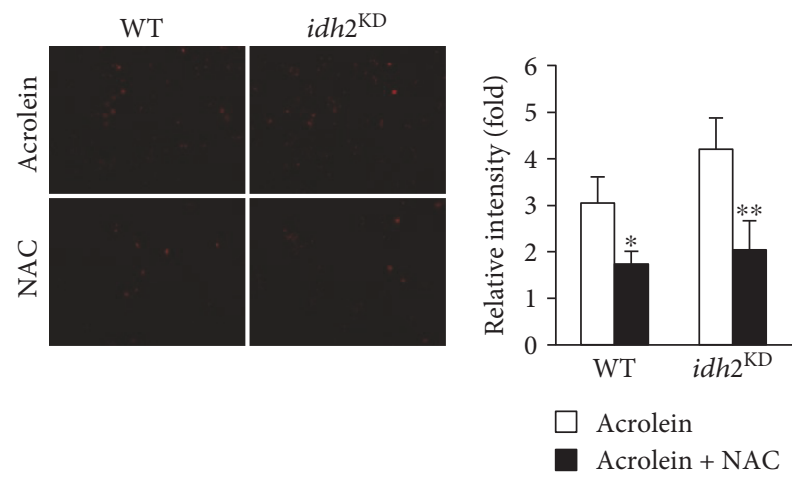

(e)

(f)

FIGURE 5: The effect of NAC on acrolein-induced toxicity in idh2 knockdown LLC cells. (a) Viability of acrolein-exposed idh2 $2^{\mathrm{KD}}$ LLC cells in the presence and absence of $1 \mathrm{mM} \mathrm{NAC}$ for $2 \mathrm{~h}$ was evaluated using MTT assay. Data are presented as the mean \pm SD of four independent experiments. ${ }^{*} p<0.05$ versus control cells exposed to acrolein. (b) Immunoblot analysis of apoptosis-associated proteins in idh2 ${ }^{\mathrm{KD}}$ LLC cells. $\beta$-Actin was used as an internal control. (c) Intracellular ROS levels were measured with DCFH-DA and fluorescence microscopy. (d) Immunoblot analysis of Prx-SO levels in idh2 $2^{\mathrm{KD}}$ LLC cell lysates. (e) Mitochondrial membrane potential of idh2 ${ }^{\mathrm{KD}}$ LLC cells was measured by incorporation of Rh-123 dye into the mitochondria. (f) MitoSox was used to detect mitochondrial ROS generation in idh $2^{K D}$ LLC cells. MitoSox fluorescence was visualized by a fluorescence microscope. In (c), (e), and (f), the average fluorescence intensity was calculated as previously described [44]. Data are presented as the mean \pm SD of four independent experiments. ${ }^{*} p<0.05$ versus WT cells and ${ }^{* *} p<0.05$, versus $i d h 2^{\mathrm{KD}}$ cells exposed to acrolein.

analysis indicated that cleaved caspase-3, cleaved caspase-9, and cleaved PARP, which represent apoptotic index, were increased in the lung tissue of $i d h 2^{-/-}$mice exposed to acrolein as compared to control. Increased expression of cytochrome c, representative of mitochondrial apoptosis, was also identified in the lung tissue of $i d h 2^{-l-}$ mice upon acrolein exposure (Figure 4(f)). These results suggest that the difference in severity of acrolein-induced lung damage depends on the presence of idh2, which influences the level of apoptosis. The major enzyme to generate mitochondrial NADPH is the mitochondrial isoenzyme, IDH2 [21]. Thus, deficiency of idh 2 may induce an imbalance of redox status in the mitochondria, subsequently increasing the vulnerability of lung cells to acrolein. To determine whether the differences in acrolein-induced lung cell death observed between WT and $i d h 2^{-1-}$ mice were associated with ROS formation, 


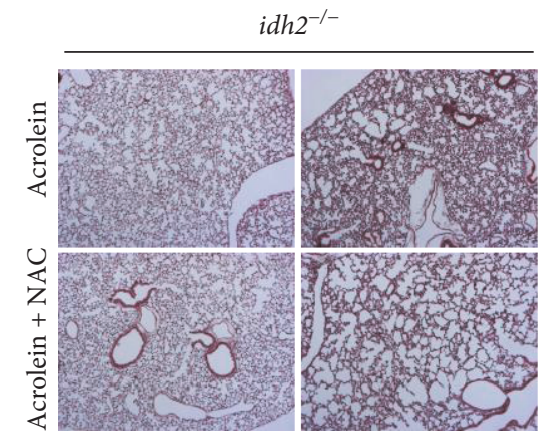

(a)

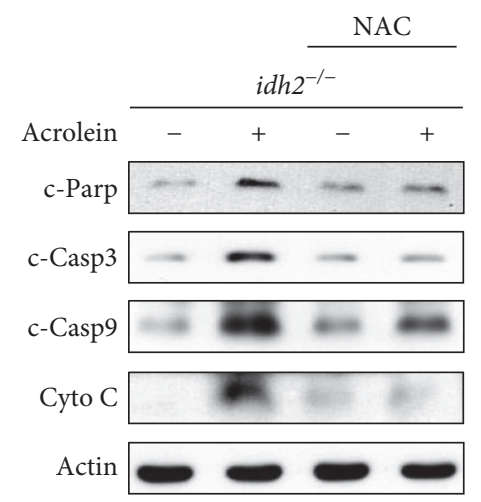

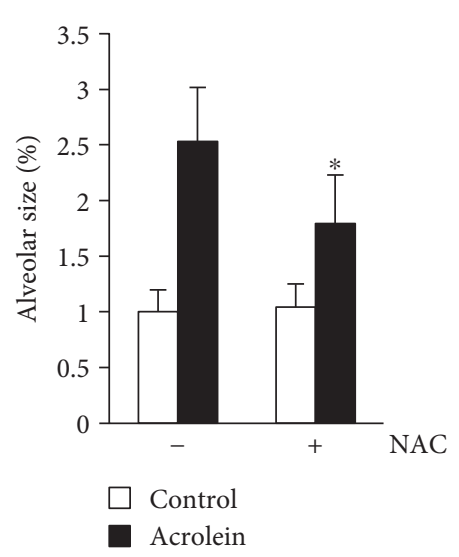

(b)

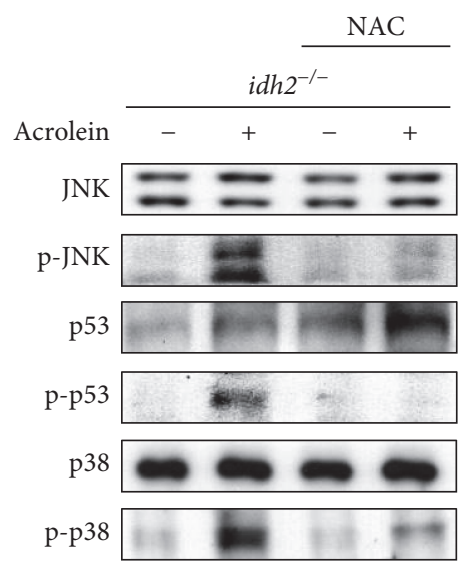

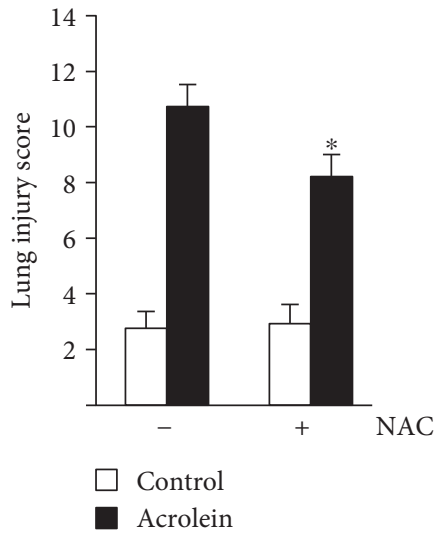

(c)

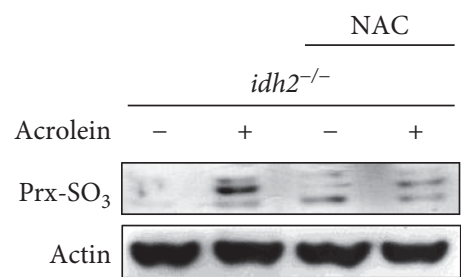

(e)

FIGURE 6: Protective effects of NAC against acrolein-induced lung damage in idh $2^{-l-}$ mice. NAC (500 mg/kg) was intraperitoneally administered to $i d h 2^{-1-}$ mice $2 \mathrm{~h}$ prior acrolein exposure. (a) H\&E-stained sections of the lung tissue after acrolein administration. (b) Emphysema in acrolein-treated lung tissues assessed by mean alveolar airspace area $\left(\mu \mathrm{m}^{2}\right)$. (c) Lung injury scores were evaluated after acrolein exposure. (d) Immunoblots comparing the levels of apoptotic marker proteins in the lung tissue extracts from idh $2^{-1-}$ mice. $\beta$ Actin was used as an internal control. (e) Immunoblot analysis of Prx- $\mathrm{SO}_{3}$ levels in the lung tissue extract from idh2 ${ }^{-l-}$ mice. In (b) and (c), data are shown as the mean $\pm \mathrm{SD}\left(n=3-6\right.$ mice in each group). ${ }^{*} p<0.05$ versus acrolein-treated and NAC-untreated $i d h 2^{-/-}$mice.

the levels of intracellular hydrogen peroxide in the lung tissue were measured using xylenol orange. As depicted in Figure 4(g), a significantly higher level of intercellular hydrogen peroxide was observed in the lung tissue of acroleintreated $i d h 2^{-1-}$ mice compared to that in WT mice. Increased expression levels of Prx- $\mathrm{SO}_{3}$, a marker of oxidative stress, were also observed in the lung tissue of acrolein-treated $i d h 2^{-1-}$ mice (Figure 4(h)). Additionally, the levels of MDA (an indicator of lipid peroxidation) and acrolein-adducted proteins, and the level of oxidative protein damage that was measured by determining the number of derivatized carbonyl groups on oxidized proteins by immunoblotting, were significantly higher in the lung tissues of acroleintreated $i d h 2^{-l-}$ mice compared to those in control mice (Figures 4(i) and 4(k)). On exposure to acrolein, the redox status of $i d h 2^{-/-}$mice was impaired more than that of $i d h 2^{+/+}$mice, as reflected by an increase in glutathionylated proteins in the lung tissues (Figure 4(1)). In addition, nitrotyrosine immunoreactivity was found to be relatively stronger in the lung tissue of acrolein-treated $i d h 2^{-/-}$mice compared with that in $i d h 2^{+/+}$mice, indirectly reflecting the higher level of reactive nitrogen species in $i d h 2^{-/-}$ mice (Figure 4(m)). Collectively, these results supported the notion that $i d h 2$ deficiency deteriorates the mitochondrial redox status that aggravates acrolein-induced colitis through apoptosis.

\subsection{Protective Effects of NAC against Acrolein Toxicity In} Vitro and In Vivo. To confirm the influence of increased oxidative stress on acrolein-induced damage, the effect of the thiol antioxidant NAC on acrolein toxicity was evaluated both in vitro and in vivo. It was previously shown that NAC reduced oxidative stress by improving the thiol redox status [43]. Pretreatment of idh2 shRNA-transfected LLC cells with $1 \mathrm{mM}$ NAC efficiently suppressed cell viability loss (Figure 5(a)) and apoptotic cell death (Figure 5(b)) after exposure to acrolein. Cellular oxidative stress, reflected by an increase in DCF fluorescence (Figure 5(c)) and Prx- $\mathrm{SO}_{3}$ level (Figure 5(d)), was significantly attenuated in acroleintreated idh 2 knockdown cells pretreated with NAC. Pretreatment of idh2 knockdown cells with NAC significantly inhibited acrolein-induced disruption of MPT, reflected by 
JC-1 fluorescence ratios (Figure 5(f)) and increased mitochondrial ROS levels as evaluated by MitoSox (Figure 5(f)). To investigate the protective effects of NAC on acroleininduced lung damage in vivo, NAC $(500 \mathrm{mg} / \mathrm{kg})$ was intraperitoneally administered to mice $2 \mathrm{~h}$ prior to acrolein exposure. The histological characteristics of acroleinadministered $i d h 2^{-1-}$ mice pretreated with NAC were compared with those of $i d h 2^{-l-}$ mice treated with acrolein alone. Compared with acrolein-administered $i d h 2^{-1-}$ mice pretreated with NAC, $i d h 2^{-1-}$ mice treated with acrolein alone showed an increased susceptibility to lung injury, as reflected by their histological characteristics (Figure 6(a)), airspace area (Figure 6(b)), and lung injury score (Figure 6(c)). In relation to apoptosis, the level of apoptotic marker proteins was evaluated in the lung tissue. The levels of the cleaved form of caspase-3, caspase-9, PARP, and cytochrome $c$ and the activated forms of $\mathrm{p} 38, \mathrm{p} 53$, and JNK in acroleinadministered NAC-pretreated $i d h 2^{-1-}$ mice were attenuated compared to those in $i d h 2^{-1-}$ mice treated with acrolein alone (Figure 6(d)). Upon exposure to acrolein, the level of Prx- $\mathrm{SO}_{3}$ was significantly lower in NAC-pretreated mice compared to untreated mice (Figure 6(e)). These results suggest that acrolein toxicity in vitro and in vivo is ameliorated by NAC through protection against oxidative stress that results from idh2 deficiency.

\section{Conclusion}

The present study demonstrates that $i d h 2$ deficiency leads to increased susceptibility to acrolein-induced toxicity in LLC cells and lung tissue in mice through disruption of the mitochondrial redox status. Having established the importance of IDH2 in the regulation of redox status and in lung tissue functions, we hereby propose that downregulation of $i d h 2$ in both in vitro and in vivo systems could be an effective model for future lung disease research. Furthermore, our study provides a useful model to investigate the potential application of NAC in the treatment or prevention of acrolein toxicity.

\section{Conflicts of Interest}

The authors declare that there is no conflict of interest regarding the publication of this paper.

\section{Acknowledgments}

This work was supported by the National Research Foundation of Korea (NRF) grant funded by the Korea government (MSIP) (Grant no. NRF-2015R1A4A1042271).

\section{References}

[1] R. O. Beauchamp, D. A. Andjelkovich, A. D. Kligerman, K. T. Morgan, and H. D. Heck, "A critical review of the literature on acrolein toxicity," Critical Review of Toxicology, vol. 14, pp. 309-380, 1985.

[2] J. M. Samet and P. W. Cheng, "The role of airway mucus in pulmonary toxicology," Environmental and Health Perspective, vol. 102, Supplement 2, pp. 89-103, 1994.
[3] M. Saetta, "Airway inflammation in chronic obstructive pulmonary disease," American Journal of Respiratory and Critical Care Medicine, vol. 160, Supplement 1, pp. S17-S20, 1999.

[4] M. K. Mohammad, D. Avila, J. Zhang et al., "Acrolein cytotoxicity in hepatocytes involves endoplasmic reticulum stress, mitochondrial dysfunction and oxidative stress," Toxicology and Applied Pharmacology, vol. 265, no. 1, pp. 73-82, 2012.

[5] T. E. O'Toole, Y. T. Zheng, J. Hellmann, D. J. Conklin, O. Barski, and A. Bhatnagar, "Acrolein activates matrix metalloproteinases by increasing reactive oxygen species in macrophages," Toxicology and Applied Pharmacology, vol. 236, no. 2, pp. 194-201, 2009.

[6] J. P. Kehrer and S. S. Biswal, "The molecular effects of acrolein," Toxicological Sciences, vol. 57, no. 1, pp. 6-15, 2000.

[7] H. Esterbauer, R. J. Schaur, and H. Zollner, "Chemistry and biochemistry of 4-hydroxynonenal, malonaldehyde and related aldehydes," Free Radical Biology \& Medicine, vol. 11, no. 1, pp. 81-128, 1991.

[8] G. Witz, "Biological interactions of alpha, beta-unsaturated aldehydes," Free Radical Biology \& Medicine, vol. 7, no. 3, pp. 333-349, 1989.

[9] H. Krokan, R. C. Grafstrom, K. Sundqvist, H. Esterbauer, and C. C. Harris, "Cytotoxicity, thiol depletion and inhibition of O6-methylguanine-DNA methyltransferase by various aldehydes in cultured human bronchial fibroblasts," Carcinogenesis, vol. 12, pp. 1755-1759, 1985.

[10] J. D. Adams and L. K. Klaidman, "Acrolein-induced oxygen radical formation," Free Radical Biology \& Medicine, vol. 15, no. 2, pp. 187-193, 1993.

[11] U. C. Yadav, K. V. Ramana, and S. K. Srivastava, "Aldose reductase regulates acrolein-induced cytotoxicity in human small airway epithelial cells," Free Radical Biology \& Medicine, vol. 65, pp. 15-25, 2013.

[12] Y. M. Go, P. J. Halvey, J. M. Hansen, M. Reed, J. Pohl, and D. P. Jones, "Reactive aldehyde modification of thioredoxin1 activates early steps of inflammation and cell adhesion," American Journal of Pathology, vol. 171, no. 5, pp. 16701681, 2007.

[13] I. Kuipers, A. S. Guala, S. W. Aesif et al., "Cigarette smoke targets glutaredoxin 1, increasing s-glutathionylation and epithelial cell death," American Journal of Respiratory Cell and Molecular Biology, vol. 45, no. 5, pp. 931-937, 2011.

[14] L. Jia, Z. Liu, L. Sun et al., "Acrolein, a toxicant in cigarette smoke, causes oxidative damage and mitochondrial dysfunction in RPE cells: protection by $(R)-\alpha$-lipoic acid," Investigative Ophthalmology \& Visual Science, vol. 48, no. 1, pp. 339-348, 2007.

[15] J. Luo, J. P. Robinson, and R. Shi, "Acrolein-induced cell death in PC12 cells: role of mitochondria-mediated oxidative stress," Neurochemistry International, vol. 47, no. 7, pp. 449-457, 2005.

[16] R. S. Balaban, S. Nemoto, and T. Finkel, "Mitochondria, oxidants, and aging," Cell, vol. 120, no. 4, pp. 483-495, 2005.

[17] D. C. Chan, "Fusion and fission: interlinked processes critical for mitochondrial health," Annual Review of Genetics, vol. 46, no. 1, pp. 265-287, 2012.

[18] S. Orrenius, V. Gogvadze, and B. Zhivotovsky, "Mitochondrial oxidative stress: implications for cell death," Annual Review of Pharmacology and Toxicology, vol. 47, no. 1, pp. 143-183, 2007. 
[19] A. Fico, F. Paglialunga, L. Cigliano et al., "Glucose-6-phosphate dehydrogenase plays a crucial role in protection from redox-stress-induced apoptosis," Cell Death and Differentiation, vol. 11, no. 8, pp. 823-831, 2004.

[20] M. Kirsch and H. de Groot, "NAD $(\mathrm{P}) \mathrm{H}$, a directly operating antioxidant?," FASEB Journal, vol. 15, no. 9, pp. 1569-1574, 2001.

[21] S. H. Jo, M. K. Son, H. J. Koh et al., "Control of mitochondrial redox balance and cellular defense against oxidative damage by mitochondrial $\mathrm{NADP}^{+}$-dependent isocitrate dehydrogenase," Journal of Biological Chemistry, vol. 276, no. 19, pp. 1616816176, 2001.

[22] J. H. Lee, S. Y. Kim, I. S. Kil, and J. -W. Park, "Regulation of ionizing radiation-induced apoptosis by mitochondrial $\mathrm{NADP}^{+}$-dependent isocitrate dehydrogenase," Journal of Biological Chemistry, vol. 282, no. 18, pp. 13385-13394, 2007.

[23] S. M. Lee, H. J. Koh, D. C. Park, B. J. Song, T. L. Huh, and J. -W. Park, "Cytosolic NADP ${ }^{+}$-dependent isocitrate dehydrogenase status modulates oxidative damage to cells," Free Radical Biology \& Medicine, vol. 32, no. 11, pp. 1185-1196, 2002.

[24] Y. Okimoto, A. Watanabe, E. Niki, T. Yamashita, and N. Noguchi, "A novel fluorescent probe diphenyl-1pyrenylphosphine to follow lipid peroxidation in cell membranes," FEBS Letters, vol. 474, no. 2-3, pp. 137-140, 2000.

[25] I. S. Kil, S. Y. Kim, S. J. Lee, and J. -W. Park, "Small interfering RNA-mediated silencing of mitochondrial NADP ${ }^{+}$-dependent isocitrate dehydrogenase enhances the sensitivity of HeLa cells toward tumor necrosis factor-alpha and anticancer drugs," Free Radical Biology \& Medicine, vol. 43, no. 8, pp. 11971207, 2007.

[26] M. Reers, S. T. Smiley, C. Mottola-Hartshorn, A. Chen, M. Lin, and L. B. Chen, "Mitochondrial membrane potential monitored by JC-1 dye," Methods in Enzymology, vol. 260, pp. 406-414, 1995.

[27] H. J. Ku, Y. Ahn, J. H. Lee, K. M. Park, and J.-W. Park, "IDH2 deficiency promotes mitochondrial dysfunction and cardiac hypertrophy in mice," Free Radical Biology \& Medicine, vol. 80, pp. 84-92, 2015.

[28] Y. Kitaguchi, L. Taraseviciene-Stewart, M. Hanaoka, R. Natarajan, D. Kraskauskas, and N. F. Voelkel, "Acrolein induces endoplasmic reticulum stress and causes airspace enlargement," PLoS One, vol. 7, article e38038, 2012.

[29] R. K. Simons, R. V. Maier, and E. Y. Chi, "Pulmonary effects of continuous endotoxin infusion in the rat," Circulatory Shock, vol. 33, no. 4, pp. 233-243, 1991.

[30] T. G. Cross, D. Scheel-Toellner, N. V. Henriquez, E. Deacon, M. Salmon, and J. M. Lord, "Serine/threonine protein kinases and apoptosis," Experimental Cell Research, vol. 256, no. 1, pp. 34-41, 2000.

[31] M. Valko, M. Izakovic, M. Mazur, C. J. Rhodes, and J. Telser, "Role of oxygen radicals in DNA damage and cancer incidence," Molecular and Cellular Biochemistry, vol. 266, no. $1 / 2$, pp. 37-56, 2004.

[32] W. Droge, "Free radicals in the physiological control of cell function," Physiology Review, vol. 82, no. 1, pp. 47-95, 2002.

[33] M. Valko, D. Leibfritz, J. Moncola, M. T. Cronin, M. Mazur, and J. Telser, "Free radicals and antioxidants in normal physiological functions and human disease," International Journal of Biochemistry \& Cell Biology, vol. 39, no. 1, pp. 44-84, 2007.
[34] A. P. Vivancos, E. A. Castillo, B. Biteau et al., "A cysteinesulfinic acid in peroxiredoxin regulates $\mathrm{H}_{2} \mathrm{O}_{2}$-sensing by the antioxidant Pap1 pathway," Proceedings of the National Academy of Sciences of the United States of America, vol. 102, no. 25, pp. 8875-8880, 2005.

[35] S. Biswal, G. Acquaah-Mensah, K. Datta, X. Wu, and J. P. Kehrer, "Inhibition of cell proliferation and AP-1 activity by acrolein in human A549 lung adenocarcinoma cells due to thiol imbalance and covalent modifications," Chemical Research in Toxicology, vol. 15, no. 2, pp. 180-186, 2002.

[36] E. I. Finkelstein, J. Ruben, C. W. Koot, M. Hristova, and A. van der Vliet, "Regulation of constitutive neutrophil apoptosis by the $\alpha, \beta$-unsaturated aldehydes acrolein and 4-hydroxynonenal," American Journal of Physiology Lung Cellular and Molecular Physiology, vol. 289, pp. L1019-L1028, 2005.

[37] J. S. Tauskela, K. Hewitt, L. P. Kang et al., "Evaluation of glutathione-sensitive fluorescent dyes in cortical culture," Glia, vol. 30, no. 4, pp. 329-341, 2000.

[38] S. Bharath, M. Hsu, D. Kaur, S. Rajagopalan, and J. K. Andersen, "Glutathione, iron and Parkinson's disease," Biochemical Pharmacology, vol. 64, no. 5-6, pp. 1037-1048, 2002.

[39] Y. C. Chai, S. S. Ashraf, K. Rokutan, R. B. Johnston, and J. A. Thomas, "S-Thiolation of individual human neutrophil proteins including actin by stimulation of the respiratory burst: evidence against a role for glutathione disulfide," Archives of Biochemistry and Biophysics, vol. 310, no. 1, pp. 273-281, 1994.

[40] A. D. de Grey, "The reductive hotspot hypothesis: an update," Archives of Biochemistry and Biophysics, vol. 373, no. 1, pp. 295-301, 2000.

[41] J. J. Lemasters, A. L. Nieminen, T. Qian et al., "The mitochondrial permeability transition in cell death: a common mechanism in necrosis, apoptosis and autophagy," Biochimica et Biophysica Acta (BBA)-Bioenergetics, vol. 1366, no. 1-2, pp. 177-196, 1998.

[42] B. B. Lowell and G. I. Shulman, "Mitochondrial dysfunction and type 2 diabetes," Science, vol. 307, no. 5708, pp. 384-387, 2005.

[43] O. I. Aruoma, B. Halliwell, B. M. Hoey, and J. Butler, "The antioxidant action of $\mathrm{N}$-acetylcysteine: its reaction with hydrogen peroxide, hydroxyl radical, superoxide, and hypochlorous acid," Free Radical Biology \& Medicine, vol. 6, no. 6, pp. 593597, 1989.

[44] H. Kim, S. H. Kim, H. Cha, S. R. Kim, J. H. Lee, and J. -W. Park, "IDH2 deficiency promotes mitochondrial dysfunction and dopaminergic neurotoxicity: implications for Parkinson's disease," Free Radical Research, vol. 50, pp. 853-860, 2016. 


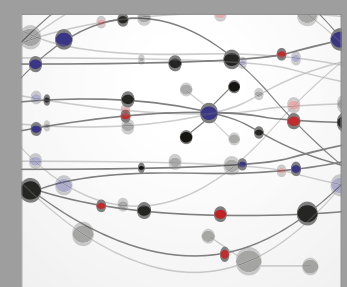

The Scientific World Journal
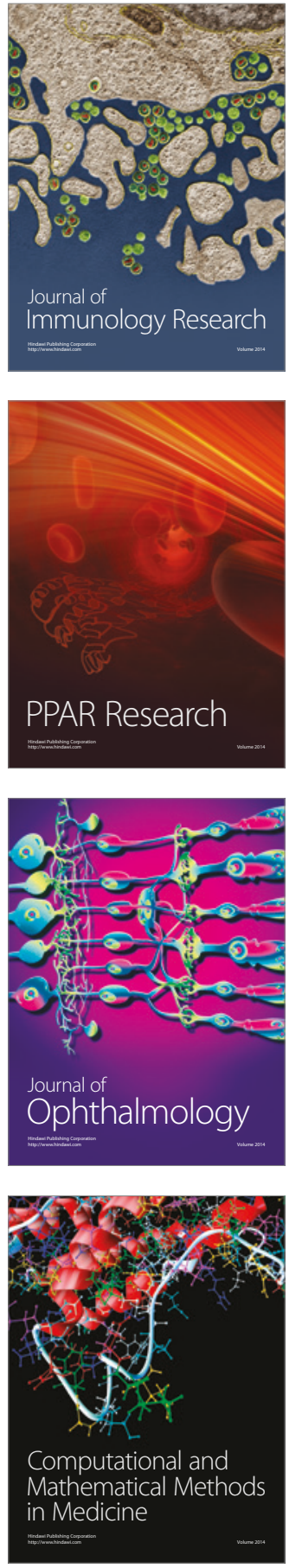

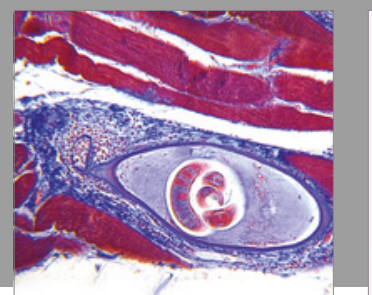

Gastroenterology Research and Practice
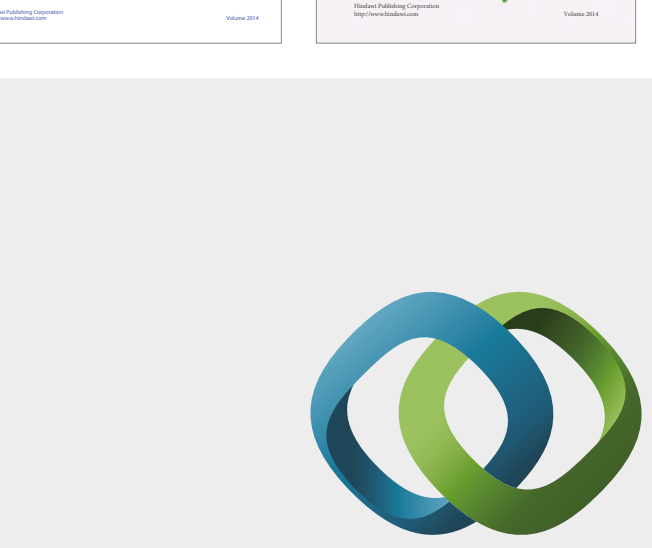

\section{Hindawi}

Submit your manuscripts at

https://www.hindawi.com
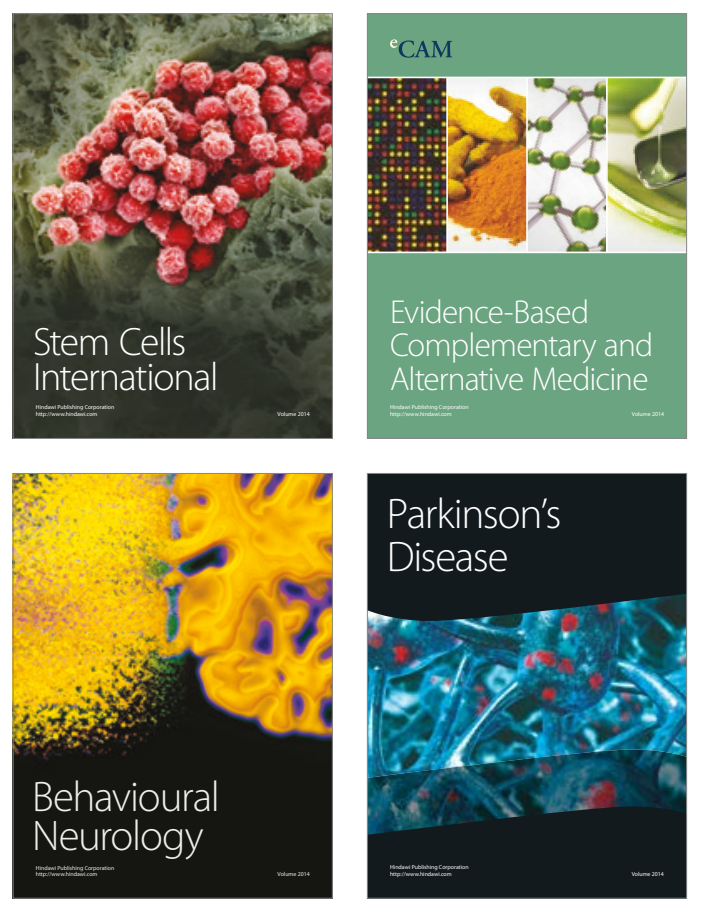
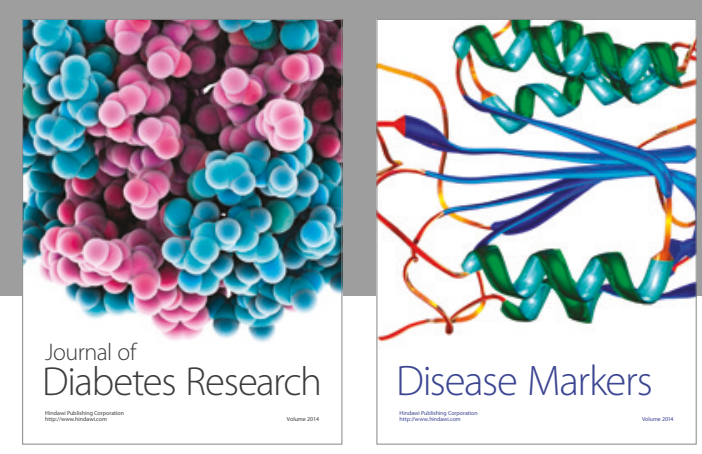

Disease Markers
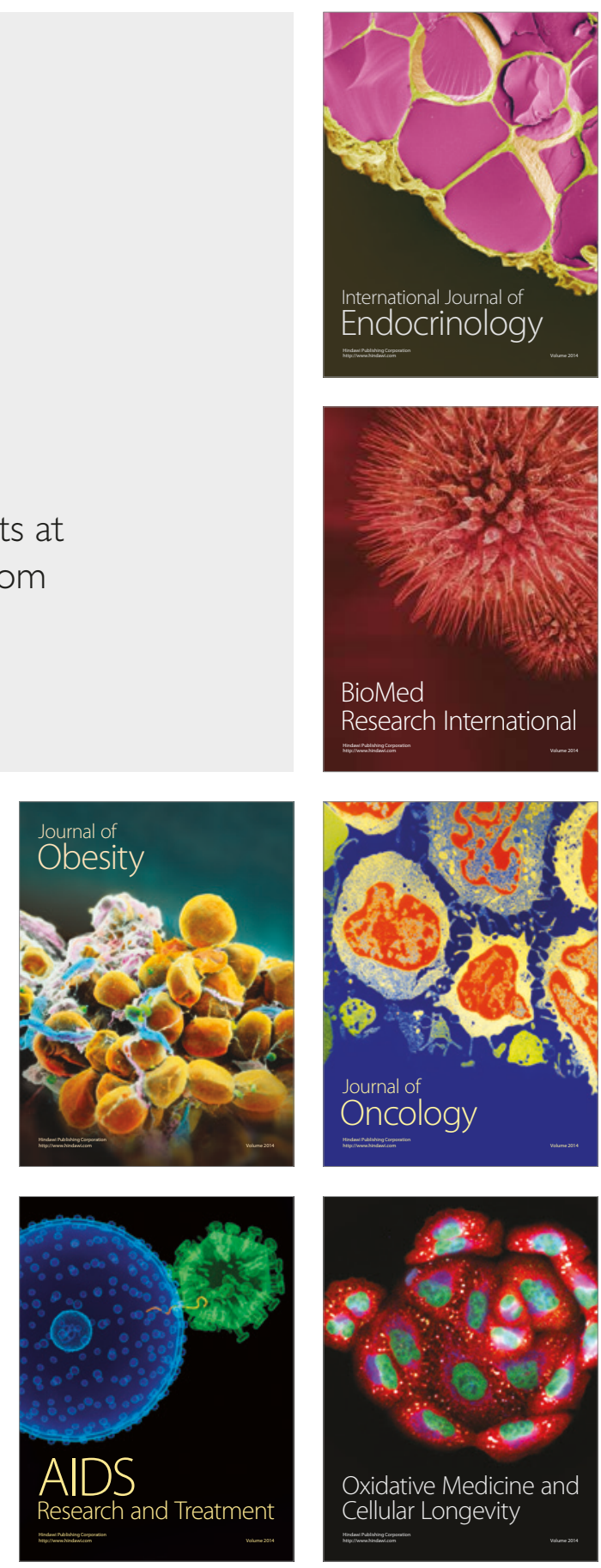